\title{
On the Future of Environmental Economics
}

\author{
Rüdiger Pethig, University of Siegen
}

\section{Introduction}

Environmental economics ( $\left.\mathrm{EE}^{1}\right)$ passed its age of infancy. In terms of monographs, proceedings volumes, specialized professional journals and papers in economic journals it grew rapidly over the last decades and established itself as a discipline based on the powerful economic paradigm and reaching beyond it to capture important economy-environment interactions. As compared to its mother discipline, economics, EE is still young but the juvenile is increasingly interested in knowing where she comes from, what her present position is and, in particular, where she will or ought to go.

After a period of strong if not stormy growth the desire for orientation and guidance increases. It materializes in new textbooks, survey articles (in specialized areas), handbooks, yearbooks ${ }^{2}$ and conferences like the present one which seek to identify and discuss the frontiers of research in EE. Focusing on research frontiers is a challenging and ambitious, if not presumptuous enterprise, directed towards outlooks on what is perceived as the likely, promising and/or necessary agenda of future research.

Let me be very clear from the outset that I am neither capable nor willing to adopt the role of a prophet, a futurologist, an 'opinion leader' or a 'trend setter'. In my view, the most promising way to think about future research in EE is to let competent senior environmental economists (EEsts) survey their specific research topics and use their experience and overview to identify what will be or ought to be ahead of us. This is, in fact, the approach taken at this conference. But what is then the possible role of a 'generalist' paper on the future of EE? In my understanding the task assigned to me is not to outperform all these experts. I rather take it as a chance, denied to them, to focus on major broad lines and issues followed by the EE profession so far and to assess its present achievements. Thus likely future developments and desiderata are unfolded in a natural way.

One way to offer reflections on the future of $\mathrm{EE}$ is to center the paper around what I perceive to be the major likely, urgent and/or desirable substantive topics on the agenda of future research such as global climate change, sustainable development, greening of business and EP issues, to name only a few. Instead, I chose the methods of analysis as the primary organizing principle starting out from theoretical concepts and their ramifications then turning to issues of interdisciplinarity and empirical relevance to finally assess the (future) impact of EE on shaping EP. Real-world environmental problems, the primary driving forces of research

\footnotetext{
1 In the present paper the following abbreviations are used: EE for environmental economics, EEsts for environmental economists and EP for environmental policy.

2 Among the many important contributions for orientation and guidance released in the 90s are: Bromley (1995), Carraro and Siniscalco (1997), Constanza, Perrings and Cleveland (1997), Cropper and Oates (1992), Daly and Townsend (1993), Kneese and Sweeney (1985/1993), Markandya and Richardson (1992), Oates (1992), Sterner and van den Bergh (1998), Tietenberg and Folmer (1997), van den Bergh (1998).
} 
in EE, are also addressed, of course, but under the premise that there is not too much dispute about what the relevant substantive issues are in EE.

The subsequent analysis as well as the citation of the pertinent literature is necessarily selective, incomplete and reflects subjective appraisals and judgments that are debatable and, in some cases, certainly controversial. Even though it is inevitable that I present my view of the future of EE I made some effort to draw on other EEsts' suggestions on the future research agenda without claiming, however, to offer a representative account. ${ }^{3}$ For obvious reasons I could not consider the contributions to the present conference. They will certainly add more color and plurality to my assessment of the future and hence promise a vivid, if not controversial discussion of some points made in the present paper.

\section{The backbone of environmental economics: Allocation theory and Coasean economics}

The basic economic paradigm as represented by Debreu's (1959) 'Theory of Value' demonstrates how decentralized coordination and allocative efficiency are achieved under idealized conditions through perfectly competitive markets. Although this neoclassical allocation theory envisages an abstract, frictionless and artificial world, it is, in my view, valuable as a framework of reference to assess the consequences of introducing imperfections. The principal deviation from the Debreu model constituting the core of EE is, of course, the presence of environmental externalities which cause the perfectly competitive markets to fail and thus define the fundamental policy-oriented task of EE as suggesting regulatory devices to overcome the associated allocative inefficiency. In the theoretical domain, Mäler (1974) is an early important contribution combining allocation theory and environmental externalities.

As is well known, the concept of externality refers to the non-market interdependence of agents' actions which is essentially synonymous to the non-existence of (certain) markets. In the context of competitive markets it is based on the assumption that agents are both pricetaking and 'externality-taking'. This view was challenged by Coase (1960) who argued convincingly that there is no reason for the absence of a market when (private and exclusive) property rights are well defined and transaction costs are zero. After the heat of the Coase debate had gone, it turned out that to a large extent EE maintained the market failure approach with the implied (Pigouvian) cause for government action because in relevant empirical cases of environmental externalities, the qualifiers of the Coase theorem, zero 'transaction costs' and well-defined property rights, did not apply. Many pollution problems affect a large number of agents rendering bargaining prohibitively costly, and/or they are related to environmental resources for which property rights are not well defined.

Nevertheless, the Coase debate (in contract to the Coase theorem) turned out to be very stimulating for the research in EE, and it has a major impact on $\mathrm{EE}$ at present and in the future for the following reasons:

(a) The property rights issue firmly links EE to law even though the economic notion of property rights goes far beyond the legal one. The research is not only about comparing the polar cases of private exclusive rights versus free access. It also focuses on intermediate cases, on communal rights, on non-encompassing or attenuated rights and on the study and design of institutions through which property rights are implicitly assigned. An interesting actual case in point is the discussion of the 'take-back rule' in solid waste management. Property rights are

\footnotetext{
${ }^{3}$ I paid special attention to several contributions in Sterner and van den Berg eds. (1998) which focus on the frontiers of EE.
} 
also particular relevant for developing countries. According to Markandya (1998, p. 464) "neither privatization nor elaborate traditional community regulations are sufficient to guarantee that the institutional changes will be sufficient to protect the natural resource base". $\mathrm{He}$ also argues that the biggest gap in our present knowledge is our limited understanding of the role of institutions which implicitly define property rights and the dynamics of institutional change.

(b) The Coase Theorem tells us that in a world with zero-transaction costs and well-defined property rights institutions neither foster nor prevent allocative efficiency. Of course, the importance of this observation rests on the reverse conclusion that if transactions costs (information costs, bargaining costs, administrative costs etc.) are significant, as in the real world, institutions do matter. Hence, different institutions will have different impacts on efficiency (and distribution) which, in turn, makes comparative institutional analysis indispensable. The focus on these issues is the programmatic objective of the so-called New Institutional Economics. ${ }^{4}$ EEsts already drew on this growing body of literature, and contributed to it, but it is a widely expressed demand and need for more systematic, in-depth analysis of institutional design, incidence and comparison. Markandya (1998, p. 470) points to our limited understanding of the role of institutions in adapting to changes in the natural and human environment and concludes that a better understanding of that process "perhaps more than any factor, is the key challenge on the research front" (ibidem, p. 470).

(c) If the number of agents involved in an environmental externality problem is not too large, each agent is directly affected by each other agent's action. As a consequence, with low or moderate transactions costs agents find themselves confronted with strategic uncertainty regarding the other agents' actions. This gives rise to bargaining or to non-cooperative reactions. Owing to the outstanding advances of game theory over the last decades, many interesting and important environmental issues have been tackled with game theoretic methods, ranging from two-person interactions which were the major focus of Coase (1960) to international environmental negotiations. ${ }^{5}$

We argued above that in its core area EE emerged as a branch of externality theory with an emphasis on the design and recommendation of policy instruments to reduce the externalityinduced inefficiencies. The amazing upswing of EE in the past decades is certainly due to the increasing empirical relevance of environmental issues. When economists discussed the Pigouvian concept of externalities in the 1950s they found it hard to come up with convincing examples. ${ }^{6}$ This situation changed dramatically, because new and large-scale environmental hazards and degradation emerged. These led to mounting dissatisfaction of the affected citizens which was then articulated and multiplied in the political arena and in the media. Even "many economists, particularly those most visible in the media, did not realize the empirical importance of externalities until the latter started making their own headlines" (Sterner and van den Bergh 1998, p. 252).

If $\mathrm{EE}$ was to play a significant role in providing relevant information for the public and for policy makers, the scientific challenges were clear: It had to come up with good advice on the

\footnotetext{
${ }^{4}$ See, e. g., the Symposium issue of the Journal of Institutional and Theoretical Economics 149 (1993): 'The New Institutional Economics: Recent Progress; Expanding Frontiers'.

5 Negotiations about international pollution problems often involve quite a large number of players and hence may be costly. But that need not prevent successful bargaining if the stakes are sufficiently high as in case of the global climate change issue.

${ }^{6}$ In the early days of EE, externality theory had the dubious reputation of dealing with exceptional and largely irrelevant phenomena (Scitovsky 1954).
} 
effective regulation of polluting activities and it had to deliver reliable information on the order of magnitude of the allocative displacement effects caused by environmental externalities and on the net-benefit of pollution control programs.

As for the design and analysis of the impact of EP instruments a huge literature has developed (Cropper and Oates 1992) which will not be discussed here. In my view, EEsts have now a very good understanding of the regulation issue both on the conceptual and applied level including the intricacies emerging when abstract policy proposals are to be implemented by real-world decision makers in a world with preexisting institutional arrangements (Hahn 1989, Shogren 1998). The professional discussion and debate on EP instruments will and need to continue, of course. ${ }^{7}$ But I believe that important insights have already been gained and therefore I see the major task ahead of us in improving the profession's impact on practical EP implementation (see section 7 below).

As for the valuation of environmental services and the benefits and costs of environmental programs it became evident that it was not good enough to tell policy makers that an 'uncompensated' externality, hence an inefficiency, "was out there". There was and still is an urgent need to be more specific about the order of magnitude of allocative inefficiencies caused by environmental externalities. To make the case for a net benefit of government intervention, environmental costs, risks and (gross) benefits need to be specified in detail and quantified. EE took on that challenge by developing methods and concepts of eliciting, estimating and measuring those costs and benefits. Non-market valuation became an exciting and vivid field of study which is still active and controversial (see Cropper and Oates 1992).

The following observations are of special interest in this context: Research in EE on the whole has grown rapidly during the last decades, but the number of papers dealing with 'valuation methods' and 'damage-benefit estimation' grew even more than proportional over time both in the Journal of Environmental Economics and Management (Deacon et al. 1998) and in the journal Environmental and Resource Economics (Siniscalco 1998). This enormous expansion of the non-market valuation literature is a 'revolutionary' development which hardly anyone could have anticipated.

The availability of various methods of non-market valuation is certainly a major achievement of EE. But can the present state of arts be considered satisfactory? How wellfounded and reliable are these methods? In spite of significant progress that has been made you will likely receive widely diverging results when different competent scholars are asked for independent cost-benefit-appraisals. More or less skepticism seems to prevail: Deacon et al. (1998, p. 388) suggested that "the 'heat' has not necessarily generated 'light' " (which leaves much room for interpretation) and they consider the contingent valuation method as one of the most controversial topics in non-market valuation. ${ }^{8}$ Sterner and van den Bergh (1998, p. 249) content that "there are still many reasons why the numbers generated are not very reliable" and Cropper and Oates (1992, p. 729) argue that "our ability to place dollar values on improvements of environmental quality is limited and imprecise". Since the profession is in doubt about the reliability of its valuation methods it is not so surprising that we have hard

\footnotetext{
7 In this future debate computable general equilibrium models will play a major role since they are very useful for ranking alternative policy measures (Conrad 1999).

8 To indicate how difficult it is to get a clear-cut appraisal of the merits and flaws of valuation methods consider the observation of Calthrop and Proost (1998, p. 338) that contingent valuation techniques have been used for estimating congestion costs for perhaps 25 years and "have been accepted in the profession long before CVM was widely applied in environmental economics".
} 
times to convince the public and, in particular, those policy makers who are skeptical of, or even entirely reject, the EEsts' conceptual approach to non-market valuation (see section 7). ${ }^{9}$

Much work on non-market valuation has been done in the context of rather small-scale projects. But the challenges grow exponentially when it comes to complex issues such as green accounting, dynamic economy-environment interaction, ecological tax reform or global climate change with the urgent need to reliably assess environmental risks, damage and abatement costs in view of dynamic interdependence and likely technological innovations. The future of $\mathrm{EE}$ and its role in shaping EP depend heavily on further substantial improvements in operational methods of non-market valuation.

\section{Environmental externalities in an imperfect world}

Imperfect information. Imperfect and incomplete information is an important fact of life in all areas of human activities, but it is particularly serious in economy-environment interactions. The Pigouvian solution lost much of its charm when its implementation turned out to be informationally infeasible. Similarly, environmental intervention with good intentions may yield bad results due to our poor knowledge of ecosystems and dose-response relationships. Whenever new environmental hazards have arisen over the last decades the initial situation was usually characterized by severe ignorance. Acid rain, ozone depletion and global warming are some of the more spectacular cases in point. Even though uncertainty cannot be completely removed, in general, multidisciplinary research efforts succeeded to reduce it significantly, in many cases. This experience is why it is reasonable to expect the veil of uncertainty to become even thinner in the future giving rise to the prospect that EP becomes more effective and better tuned toward supporting a sustainable development.

In the context of theoretical EE, incomplete information and uncertainty has been introduced into rigorous analysis in a systematic non-trivial way. In many cases, EE followed and applied advances in main economics, most notably in risk analysis, agency theory and game theory when strategic uncertainty is combined with incomplete and asymmetric information. EE adopted a pioneering role in the theory of decision making under the threat of irreversibility and the prospect of improved information in the future. In my view, the analytical consideration of informational aspects helped a lot to better assess and compare environmental policy options and should therefore be continued in future research.

It is worth mentioning that institutional arrangements and EP instruments, in particular, may induce or discourage agents to use or elicit environmentally relevant private information for achieving satisfactory or even efficient results. An ambitious and intellectually appealing approach was the design of demand revelation procedures (Green and Laffont 1979) which do not seem to have reached the level of practical relevance, however.

Imperfect competition is a particularly important real-world phenomenon. Long before environmental issues became a major concern, economists had realized that neither perfect competition (as in the referential allocation theory) nor monopoly are relevant market structures in most real markets. Globalization tended to reduce the relative size of firms in expanding markets but at the same time quite a few firms grew even faster and became powerful multinational agents while smaller firms retained considerable discretion in (national) submarkets. Issues of industrial organization and (environmental) regulation arise where firms

\footnotetext{
9 The acceptability problem is exacerbated by ill-founded studies throwing numbers into the public debate that do not even pass the laugh test.
} 
and regulators are players acting strategically and trying to take advantage of private information (see above). Major advances in game theory triggered an ever growing literature on industrial organization which trickled down, eventually, to EP issues (Carraro and Siniscalco 1997).

The pertinent literature is still small but growing. It applies partial equilibrium analysis almost exclusively (which is appropriate for all policy issues with small ramifications across major markets) and is (as yet) mainly theoretical. Its message is, in a nutshell, that "no general conclusion about the effects of EP can be derived, because the presence of multiple market externalities, both positive and negative, makes the use of a single policy instrument, designed to correct for the environmental externality, largely sub-optimal. As a consequence, EP needs to be designed so as to take into account the "characteristics of the specific market and the specific environmental phenomena to be regulated" (Carraro 1998, p. 368). I certainly agree to Carraro (ibidem, p. 376), that though theoretical advances are necessary "an extensive empirical research program is probably even more important."

Drawing on the experience in industrial organization (on other than environmental issues) in recent years a very large variety of models has been advanced focusing on the same or similar issues but yielding different, partly incompatible implications. Empirical testing and analysis which was at the heart of the pre-game-theoretic industrial organization literature has hard times to keep up with the stormy theoretical development to filter out its empirically relevant aspects.

EE has yet to establish an empirical branch of industrial-organization related analysis. That is a major task for the future because I expect the theoretical literature continuing to grow fast confronting us with a frustrating plurality of diverging results and recommendations whose empirical relevance is an open question. On the other hand there cannot be any doubt that imperfect competition needs to be addressed more systematically than in the past for the benefit of the empirical relevance of $\mathrm{EE}$ and at the cost of devaluing our traditional, less complicated paradigm of perfect competition.

Preexisting public policy distortions in the competitive economy. Whenever environmental regulation affects several major markets and their interaction as e. g. in case of fossil fuel regulation, general equilibrium analysis is indispensable. To tackle the vast complexity of general interdependence, researchers quite often seek comfort in the world of perfectly competitive markets. ${ }^{10}$ But even with this analytical relief, determining the impact of environmental regulation gets very complicated when the empirically obvious is accounted for, namely that (quite a large number of) distortions preexist. How messy the analysis of secondbest is, was first shown by Lipsey and Lancaster (1956). Public finance economists made the same experience when they investigated the intricacies of e. g. optimal taxation and welfareenhancing incremental tax reforms.

To the best of my knowledge EEsts did not make major efforts to embark on this kind of complex general equilibrium analysis until, a few years ago, the prospect of a double dividend from shifting the tax mix towards environmental taxes while keeping total tax revenue constant electrified the EE community. In a pioneering paper Bovenberg and de Mooij (1994) arrived at the surprising verdict that "an environmental tax reform tends to exacerbate rather than to alleviate pre-existing tax distortions" (ibidem, p. 1085). This still vivid, ongoing debate on the

10 There are ways to include market imperfections in general equilibrium analysis that will not be discussed here. See e. g. Ginsburgh and Keyzer (1997). 
double (or multiple) dividend is well suited to illustrate some important general theoretical as well as empirical challenges:

(i) It demonstrates one more time that research hot spots and hence the future directions of EE are hardly predictable. The basic idea regarding the possibility of reaping a double dividend has been advanced long time ago, e. g. by Tullock (1967), but it was not put to a rigorous check by means of general equilibrium analysis until 1994.

(ii) We learnt the lesson one more time that if significant market interdependencies are involved, partial equilibrium analysis may be misleading. Those who 'endorsed' the double dividend using partial equilibrium analysis based their arguments on sound economic intuition which turned out, however, to be incomplete.

(iii) Without any intention to diminish the merits of the Bovenberg and de Mooij (1994) analysis it needs to be mentioned that its central assumptions are fairly restrictive, notably the linear technology, the absence of waste abatement and the special structure of the utility function (implying that a labor tax is second best if there is no emission tax). As a consequence we observe an ongoing discussion (to which the authors of the pioneering paper contributed themselves) about confirming or challenging the robustness of the general equilibrium results applying both qualitative analysis and computable general equilibrium models.

Two important questions arise with the potential to impact on the future research in EE:

- Will we succeed in settling the robustness issue satisfactorily or do we get lost in the stormy waters of second best in which 'anything can happen'?

- If we succeed, can we hope to get reliable quantitative information about both the sign of the dividends and their empirical order of magnitude?

The last point raises even deeper and more general questions: We live in economic systems with many market imperfections, partly created by government interventions, that have no direct or intentional effects on environmental issues but may, via ubiquitous interdependence effects, well impact on them indirectly. For example, changes in major social policies (such as health care or social security) may have side effects on EP. Which imperfections of the thirdbest world matter and which can safely be neglected? What are the future standards, regarding the exclusion of interdependence effects in second-best worlds, in economics as well as in EE, for policy appraisals?

Unfortunately I raised many questions and provided few or no answers. But I strongly subscribe to Blackorby's (1990, p. 769) statement: "If we say that, in a second-best world, anything can happen and that that is too complex, then we will be making policy recommendations that are based on completely fraudulent thinking. Such ostrich-like behavior risks doing more harm than good to society and certainly would relegate the study of economics to some arcane backwater of intellectual activity". Hence there is much work ahead of us!

\section{The dimensions of distribution, space and time}

Distribution. Environmental economic analysis often appears almost synonymous to advocating allocative efficiency, where efficiency ranges from conventional cost effectiveness of pollution control to the public provision of non-marketed environmental goods. Efficiency certainly is and remains an important issue for EE and is quite well understood because our economic paradigm with its link to welfare economics is perfectly suited to tackle it. The 
economic paradigm neatly separates distributional from efficiency issues via the second theorem of welfare economics. This theorem is clearly an important insight, but similar as the optimal taxation literature emerged from acknowledging the empirical fact that nondistortionary (or lumpsum) taxes are hardly observed in real economies, EEsts need to account more seriously for the empirical fact that the implementation of any EP creates losers that are not, in general, compensated by lumpsum or other transfers. In a second-best world it is difficult, if not impossible, to separate considerations of efficiency and equity (Blackorby 1990). Consequently, policy recommendations cannot be made without interpersonal comparisons of utility.

There are, of course, studies on distribution of income and wealth, poverty, equity, social justice and related issues both in main stream economics and in EE. The pertinent literature in EE as addressed e. g. by Cropper and Oates (1992, p. 727 n.) and by Markandya (1998) is quite small, however, as compared to the efficiency oriented literature. One would have no reason to worry about that if we had a good knowledge about the interface of environmental and distributional issues. But according to Markandya (1998, p. 460) the "linkages between poverty/income distribution and EP are ... not as well understood as they need to be". In my view, distributional issues should obtain greater attention in the future EE research for several other reasons:

(i) Policy makers have either perceptions of social justice of their own or take account of those prevailing in their constituency, and/or they care for distributional impacts to secure their political career or survival. The polluter-pays principle with its pronounced distributional implications seems to have some support in the political arena, but it did not turn out to be an undisputed normative guideline in political action. ${ }^{11}$

(ii) Each EP proposal whose prime goal is efficiency has distributional side effects that can and need to be accessed both in conceptual incidence analysis and empirical studies to inform policy makers. If sound research-based information is not available the political action proceeds on the basis of somehow (ill-)perceived distributional conjectures. Quite often such assessments capture only direct and immediate effects and thus may result in flawed decisions.

(iii) To be more specific, consider the case of siting economic facilities with the potential of causing environmental hazards in the neighborhood of the site (e. g. hazardous waste landfills, waste incineration plants, nuclear waste deposition sites) or causing environmental degradation (e. g. construction of new highways or bypasses, deforestation, deregulation of land use restrictions). Even if the net benefit of such projects is positive, the interregional distributional effects may differ dramatically as becomes evident in controversial political debates. In the past, EEsts offered little systematic and in-depth analysis of the distributional impacts of such siting decisions.

(iv) If EEsts restrict their analysis and advise to efficiency aspects of their EP proposals they may risk being misunderstood as taking a partisan stance in the political (distributional) debate even if their exclusive focus on efficiency is made explicit.

(v) Acknowledging that special interest groups and hence distributional considerations are relevant in the political decision making process or, as some political economists argue (e. g. Brunner 1978), even dominate efficiency arguments has important consequences for the future

11 That is particularly true in cases of transboundary pollution, but defection from that principle can also be observed in cases of purely domestic pollution. For example, a few years ago German farmers were subsidized to lower the groundwater pollution they caused and this program was defended by some EEsts (e.g. Bonus 1986) on the grounds of the 'Coasean principle of reciprocity'. 
research program of those EEsts who strive for a greater impact of EE on the implementation of EP: The distributional consequences of proposing institutions and/or instruments of EP need to be systematically considered in the phase of their design in an effort to improve their political acceptability. This issue will be discussed more broadly in section 7 .

So far our focus was on intratemporal distribution. In the sustainable-development literature issues of intertemporal/intergenerational distribution and equity play a major role, too, or are even central to the ongoing debate. To elaborate on this topic is beyond the scope of the present paper, but it highlights the point that the preoccupation with efficiency might have been pushed too far in the past.

Spatial analysis. It is neither a new nor an original insight that economic activities as well as ecological systems develop in space and that in terms of quality and quantity, economic and ecological processes change and interact in space. It is obvious that space has been accounted for in $\mathrm{EE}$ in a variety of significant ways (see e. g. Siebert 1985). Most notably, transboundary pollution in regional, international and global settings was and still is ranking high on the agenda of EE. But even if pollutants don't cross boarders trade in productive factors and commodities renders national EPs interdependent with the potential of strategic behavior on the side of governments (race to the bottom?).

Quite apart from these issues with a fairly abstract connotation to space ${ }^{12}$ there are important economy-environment interdependencies with specific and more concrete spatial dimensions that have not yet received the attention of EE research they deserve (Bockstael 1996). Obviously most ecological systems as well as economic activities use up land, and the historical development is characterized by a process of ever increasing land use demands for economic purposes, quite often at the expense of ecological systems and natural habitats. Not only continues this expansionary process but also are habitats devalued by land use fragmentation. Following Deacon et al. (1998, p. 394) there is a great need to know more about how "habitat values depend on the spatial configuration of land in different uses", what are "the determinants of changes in land use configurations" and which are the "appropriate policy instruments to influence these processes". It should be also emphasized, as do Agee and Crocker (1998, p. 263), that there are mediating behavioral interactions which link economic and ecological systems (in space) and which can make significant differences in system responses. To sum up, "the spatial dimensions of resource use may turn out to be as important as the exhaustively studied temporal dimensions in many contexts. Curiously, the profession is only now beginning to move in this direction" (Deacon et al. 1998, p. 393).

Intertemporal analysis. The first rigorous answer to the intellectual challenge of better understanding where market forces drive an economic system in the long run was the neoclassical growth model. It focused on the explanation of capital accumulation, but its reference to technical change as 'manna falling from heaven' was a major reason for the research community's fading interest. In addition, the neglect of environmental and natural resource constraints to growth made this theory unacceptable from an EE point of view. The 'Limits to Growth' (Meadows et al. 1972) marked an important turning point, and with advances in optimal-control techniques issues of long-term (environmental) resource use where tackled since the 1970s. An important further impulse was the introduction of the concept of sustainable development which shifted the focus of the analysis towards the dynamics and long-term development of the ecological system. Among the latest 'innovations' in

12 Bockstael (1996, p. 1169) quotes V. K. Smith as having noted "that economists, when they do deal with spatial distribution, introduce it as a constraint - as an exogenous fact, but rarely attempt to explain it as a dimension of an economic decision". 
intertemporal analysis is the application of endogenous growth theory from main stream economics to environmental economic issues (Carraro and Siniscalco 1997). It demonstrated that human capital formation along with increasing returns in production gives rise to the possibility that 'dematerialization' of production (and consumption) may reconcile permanent growth and a finite resource base.

Endogenous growth theory leads us to focus our attention on what determines human capital investment and productivity. Even though this new perspective led some EEsts to be slightly more optimistic in their assessment of long-term scarcity of natural (renewable and non-renewable) resources, the proposition that technology will bail us out has not yet a sound theoretical and empirical basis (Deacon et al. 1998, p. 393). Changes in technology over time, in particular 'pollution reducing' technological innovations, and their determinants are, in my view, the single most important factor for easing the growing stress the economic system imposes on the ecological system in the long run. To better understand these issues strong research efforts are being made and need to continue along various routes. One promising line of research focuses on individual firms and their incentives to innovate, another on the impact of interacting firms on innovation (industrial organization literature); other studies investigate how technological innovation responds to natural resource scarcity and other social needs. Unless our knowledge about all these issues is substantially improved the policy guidance of EEsts on long-term sustainable development remains rather limited.

Intertemporal analysis can also relate to changes in preferences over time. Long before the appearance of EE, but also since then, there were always researchers who challenged the assumption of time-invariant preferences. The stubbornness with which most economists and EEsts upheld their credo that "de gustibus non est disputandum" (Stigler and Becker 1977) raised the suspicion of some advocates of changeable preferences, e. g. Norton et al. (1998), that EE shows traces of dogmatism. Here is not the place to discuss this issue in appropriate depth. I content myself with observing that in my view the assumption of time-invariant preferences is a convenient methodological concept suitable for many purposes of investigation. Besides, all those who find that procedure not acceptable are invited to present alternatives and convince the stubborn part of the research community about the supremacy of their approach.

So far I focused mainly (too much, perhaps) on the dynamics of the economic system. Needless to say that natural and ecological system is also characterized by intertemporal stockflow relationships with Lotka-Volterra models of population growth as classical prototypes and (dynamic) predator-prey models as reflections of intra-ecological interdependence (Clark 1990). Similar concepts were applied to model stock-flow pollution issues. The important issue is, of course, the interaction of the dynamics of both the economic and the ecological systems. After all, the economy is sustainable if and only if the ecological system is sustainable. We find studies with hardly any interaction, with unilateral dependence, but also studies that model interdependence, even though typically on a highly aggregate and hence rudimentary level where the ecological model is usually much less structured than the economy. ${ }^{13}$ With such

\footnotetext{
13 Even the static reference model is a model of rudimentary interdependence: The release of pollutants into the environment deteriorates the state of the 'ecological system' as indicated by a variable 'pollution level' or 'index of environmental quality'. Then the ecological system 'strikes back' causing 'environmental damage' in terms of loss of utility or reduction in productivity which triggers reactions of economic agents, in turn. Therefore I am willing to give a bit more credit to the achievements of the basic reference model of EE than Agee and Crocker (1998, p. 262) who suggest that "the standard Walrasian paradigm ... views natural systems as vessels carrying interacting economic agents as passengers and asks only whether allocation institutions are
} 
models, issues of sustainability (including the threat of irreversible damage to the ecological system) can be and have been addressed, but there are good reasons to argue that a satisfactory approach requires a much more elaborate framework of analysis concerning the ecological system and its interaction with the economy.

In recent years new dynamic or evolutionary approaches emerged that aim at accomplishing just that by radically trespassing boarders and barriers of conventional environmental economic analysis. For example, Perrings (1998) draws on recent highly technical work on ecological and economic dynamics. Preferences and technologies are no longer taken as exogenous and constant in his approach, and he models economic development and environmental change as interdependent stochastic evolutionary processes producing discontinuous path-dependent changes and repercussions in both systems. Sustainable development is addressed as a policy directive to "sustain the joint systems in a desirable state or avoid it being locked-into an undesirable state" (Perrings 1998, p. 516). The concept of resilience is analyzed helping to bridge the gap between the ways ecologists and economists used to think about stability issues (Levin et al. 1998).

Such research programs break new ground at the core interface of economics and ecology. In my view, they are important, ambitious and have the potential of significantly impacting on the future of EE. How far this potential can be developed, remains to be seen, however, because the more heavy mathematical machinery is used (e. g. Markow processes in Perrings (1998)) the more limited their capacity might turn out to be in producing ecologically and economically meaningful results.

\section{Environment-economy interactions and interdisciplinarity}

The work referred to in the last paragraphs is important for the future research in EE, because it places the interaction of the ecological and economic system at center stage rather than focusing on the economic system with a small environmental appendix. This raises the more general question of how serious EEsts have been, are and should be about reaching beyond economic analysis. Again, I cannot offer here a thorough and balanced account of this issue which, in fact, would require to undertake a major research effort in its own right (an effort that would certainly be both desirable and rewarding). Instead, I content myself with the following 'stylized' appraisals:

(i) As seen from base zero, EEsts achieved substantial insights, both on the conceptional and empirical level, in the links between the environment and the economic system and on EP schemes to cope with those links. But in its core domain EE tended to place more emphasis on analyzing the economic system than on environment-economy interactions.

(ii) To study environment-economy interactions does not mean to endorse 'outdated' economics. The continuous injection of advances in both theoretical and empirical economics into $\mathrm{EE}$ is vital for the future of $\mathrm{EE}$. The EE research community should not retreat into a niche seeking shelter against new developments in economics.

(iii) There is a high priority need in EE to correct the preoccupation with economic issues by focusing more than in the past on environment-economy interactions including the impact EP and the behavior of economic agents have on these interactions.

designed to cause the passengers to be fully accountable for the direct consequences their choices have for their fellow voyagers. The Walrasian paradigm sets aside the state of repair of the vessel". 
(iv) To improve the analysis of environment-economy interactions, the empirically relevant and up-to-date knowledge of ecological and natural sciences needs to be used and integrated into EE in a more systematic way.

While point (ii) above does not seem to be consensual among EEsts (Sterner and van den Bergh 1998, p. 254) I observe acclamation for point (iii) from many EEsts and from ecologists, a fortiori. Quite a few steps have already been taken in this direction, but the list of desiderata is long as exemplified by the following sample of demands:

- "Extractive and environmental components of resource decisions should be considered simultaneously" (Deacon et al. 1998, p. 387);

- In fishery management more attention should be paid "to ecological services, biodiversity and recreation possibilities" (Eggert 1998, p. 399).

- In valuation, "more complex issues related to ecosystem functions, services and characteristics need more attention" (Sterner and van den Bergh 1998, p. 257);

- Since economic and natural systems are linked by mediating behavioral interactions, "a systematic empirical accounting of mediating behavioral linkages can make significant differences in system responses that are estimated and in the economic valuations attached to these responses" (Agee and Crocker 1998, p.263).

The ambitious goal of strengthening the focus on economy-environment interaction cannot be achieved unless EEsts take a closer look at, and adopt insights, concepts and techniques developed in, the ecological and natural sciences (point (iv) above). This process is under way since, as Sterner and van den Bergh (1998, p. 255) observe correctly, "the very nature of the subject and real-life problems drive EEsts in the direction of interdisciplinary work." But some doubts are in order about whether that 'drive' for the necessary and desirable interdisciplinary work develops sufficient momentum without devoted extra efforts. Present deficits are not hard to identify as e. g. the biological models commonly used in EE: "Economics have largely stuck with simple paradigms that most biologists regard as useful pedagogical metaphors, but of little practical value." (Deacon et al. 1998, p. 391). ${ }^{14}$ In other words, it is desirable to shape the EE research in closer communication and contact with the state-of-the-art work in ecologically relevant disciplines.

If EEsts follow this pladoyer for closer contact with other relevant disciplines in the field of environment-economy interactions the prospects would be favorable for narrowing the gap of communication deficits and lack of mutual understanding. Some might even already see a joint approach to the common subject matter of study at the far horizon. Even though I endorse emphatically the quest for more interdisciplinarity, I have little illusion about how hard this is to accomplish. EEsts have ample experience with both the difficulties and benefits of transdisciplinary communication. For example, referring to economics and ecologyepidemiology, Agee and Crocker (1998, p. 262) observe, that "the relationships between the two disciplines can be characterized as much by tensions and recriminations about what knowledge is and how to get it than by mutual respect and reinforcement."

\footnotetext{
14 While this is a valid criticism I am reluctant to subscribe to sweeping demands to discard of all simplifying analytical tools. A remarkable strength of economic analysis has always been to vary the degree of abstraction in line with the purpose of investigation at hand (and, admittedly, with an eye on tractability). For example, production technologies with factor substitution may be reasonable to assume in aggregate analysis even though engineers may have reasons to reject that assumption at the microlevel of individual firms.
} 
Let me illustrate the tensions about how to get knowledge for the case of placing values on services rendered by nature and ecological systems. In section 2 I pointed out how central this issue is for EE and how vital and urgent further progress in methods and techniques is to get beyond unsatisfactory statements of the type: 'We know that there is an environmental externality out there creating an inefficiency but, unfortunately, its order of magnitude is largely unknown'. The dispute within EE is about the best means and methods to reach the joint goal, namely measuring the (marginal) values economic agents attach to environmental goods which the market would have elicited without any research effort if it had not failed. Other researchers in the field, notably non-economists, challenge or even reject the EEsts' concept or 'philosophy' of value measurement altogether and consequently are not at all interested in debates about the appropriateness of means to reach a goal they consider inappropriate. $^{15}$

There is nothing wrong about the existence of different views on how to get knowledge. This creates a competitive situation, and as economists we are on our home turf when talking about the benefits of competition, how it spurs efforts, creativity etc. My suggestion is that we should try, by means of constructive further research, to demonstrate that our product is superior to the competitors' ones rather than try to let our product look better by criticizing theirs. While this competitive-market analogy has some merits I should point to its limits, too: Endorsing, and calling for, interdisciplinary work implies, of course, to overcome noncooperative behavior. In fact, a cooperative approach is called for!

Differences of paradigmatic approach are mainly a barrier to interdisciplinary communication and work for those researchers who feel an urge to think in narrowly defined 'schools' and 'sub-schools'. I suggest to think of the economic paradigm (without attempting to define it) as a broad, useful and powerful 'corset' guiding our research that is very flexible and capable of absorbing new components and interdisciplinary impulses. To put it differently, the interdisciplinary dialog need not and must not be barred by methodological differences in approaching the joint field of research. There are many indications (such as Faber and Proops 1990, Arrow et al. 1995 or Levin et al. 1998) that this dialog is on. Even in the controversial field of non-market valuation I referred to earlier a fruitful communication and cooperation is emerging between ecologists and economists to improve linkages between ecological and economic valuation methods (Bingham et al. 1995). This communication ought to be encouraged.

A few years ago the German Science Council evaluated the 'Environmental Sciences' in Germany. In its detailed and voluminous report (Wissenschaftsrat 1994) a major finding was that university research in this field is essentially compartmentalized along department lines and hence lacks interdisciplinarity while research institutes outside universities showed a better interdisciplinary performance. The Council's clear message was that environmental sciences in academia need to shift more towards interdisciplinarity. To bring about such a shift it is certainly important to know what the obstacles are to interdisciplinary work. For one thing, it is always easier and more enjoyable to communicate among people who 'speak the same language' (i. e. use the same methods) than to undergo the effort of becoming 'multilingual'. Moreover, young researchers are often reluctant to trespass into other disciplines because "academic careers are clearly tied to proficiency within rather than between disciplines"

\footnotetext{
${ }^{15}$ EEsts who are still engaged in developing methods of non-market valuation are compared by Sagoff (1994, p. 307) "to the Japanese soldiers who where found on islands in the Pacific years after the end of the Second World War, still fighting although the mainland had surrendered and the cause had long since been lost".
} 
(Sterner and van den Bergh 1998, p. 255) (When those young scholars have become senior researchers they have become reluctant to learn 'foreign languages', unfortunately).

\section{Empirical relevance of environmental economics}

EE owes its very existence and relevance to real-world environmental problems that concerned and still concern the broad public, the media and political decision-makers. Since it is not likely that the pressure of economic activities on the ecological system will diminish, the challenge for necessary and useful research will probably even increase in the future. ${ }^{16}$ Deacon et al. (1998, p. 383) are certainly right in observing that "research on EE will be driven by policy questions, as has generally been true in the past." In that broad sense the subject matter of EE did not and will not lack empirical relevance. On the other hand, it does not follow from the heavy emphasis of EEsts on policy questions that empirical research is dominant in EE. In fact, we have the intriguing situation that even most theoretical papers, including very abstract ones, suggest policy implications, EP instruments or institutional arrangements as a cure for some inefficiency under scrutiny so that one might get the impression, EEsts form a community of self-declared policy advisers not necessarily asked for their advice and often without serious intentions to promote their own recommendations in the down-to-earth real-world process of policy implementation.

This phenomenon need not be criticized if one is willing to accept the distinction between and to admit the necessity of - basic and applied research as is widely common in the natural sciences. My experience is, however, that some EEsts devoted to empirical research find this position not easy to accept. Having said that, I hasten to add, that policy advice from the theoretical ivory tower remains useless and sterile

(i) if it is not accompanied by systematic research efforts to test theories and policy proposals for their empirical 'validity'

(ii) and if there is not an 'operative chain' of research dispersion from the ivory tower to the level of actual practical policy implementation.

As economists, we should not find it too difficult to acknowledge the necessity and advantages of the principles of division of labor and comparative advantage. But I join those who are concerned about whether the self-assignment process of researchers to the tasks I described above ensures that all these tasks are taken care of in an appropriate way. I don't pretend to know what the right division of labor should be, but there is some concern about theoretical knowledge piling up faster than testing the pertinent hypotheses and theory implications. It cannot be a sensible end in itself to produce an ever increasing diversity of models and theories. We should rather strive for accumulating empirically sound theoretical knowledge. Where do we stand on this account and where are we heading to?

Rather than offering a balanced answer to this important question let me indicate my skepticism about our past achievements by referring to Sterner and van den Bergh (1998) who put together a special issue of the journal 'Environmental and Resource Economics' on 'Frontiers of Environmental and Resource Economics' choosing the programmatic and

\footnotetext{
16 In the past decades a number of new serious environmental risks and threats were identified that had not been expected or anticipated - neither by the public nor by the academic research community. I refrain from speculating on how this process will continue, but the currently known threats are severe enough to support the claim that economic pressures will put the ecological system under increasing stress.
} 
ambitious subtitle 'Testing the Theories'. This special issue left me with the impression that, at present, theory testing plays a minor role only in EE. There is much work ahead of us!

The increasing specialization within the field of EE produces many important new insights and is also an appropriate response to the real-world complexities of the issues to be tackled. But it involves the risk, at the same time, that applied work doesn't take due notice of theoretical advances and vice versa. Both fields are important, in my view, but they must not follow disconnected autonomous paths driven by immanent forces without much regard of the other. Good theory needs to 'trickle down' to application and policy implementation, and theory design should be well responsive to needs and pressures at the level of application. There are only very few individual researchers whose research program bridges the entire gap. It is therefore crucial that a sufficient number of researchers are positioned at intermediate levels of abstraction to secure the two-way communication among theorists and applied economists.

The dramatic advances in computer technology during recent years triggered a huge productivity increase in quantitative applied work boosting data processing, econometric work and, in particular, computable general equilibrium analysis (Conrad (1999)). This development is to be welcomed with regard to the empirical relevance of EE, and it tends to increase the attractiveness of $\mathrm{EE}$ for the political decision making process which appears to respond to 'numbers' much more than to qualitative information. As seen from the scientific perspective, the fundamental question is, of course, how reliable the quantitative information is that we are able to provide. Reliability clearly depends on the empirical soundness of the underlying theories which brings us back to the issue of hypothesis testing. We clearly need both: Producing numbers on the basis of existing theories and improving those theories to generate more reliable numbers. The finding by Deacon et al. (1998, p. 390) that the field of non-market valuation research "has been dominated by application rather than testing and refining of the basic theory" suggests to me that in the future more emphasis needs to be placed on the latter.

The methods of computable general equilibrium analysis, as applied e. g. to energy taxation or transportation economics, have been significantly expanded and refined during the last decades, and this process will certainly continue in the future. The current status of computable general equilibrium models with respect to reliability is also an important issue, of course. My impression is that this area is still characterized by competing approaches which, if applied to the same issue may generate significantly different results. Conrad (1999) contends that computable general equilibrium analysis is useful for comparing alternative policy instruments but not for economic forecasts. He sees a large potential for future research in developing such models with features like imperfect competition, endogenous technological change, infrastructure and overlapping generations. But he also warns against too much optimism because "the more complicated the model, the more it becomes a black box".

The assessment of empirical relevance of EE has yet another aspect which soon leads into deep waters of methodology into which I want to take a quick dip only. I mentioned earlier that EE is firmly based on a well developed economic paradigm which - as most of us will agree - satisfies Sen's (1985, p. 341) desideratum: "We want a canonical form that is uncomplicated enough to be easily usable in theoretical and empirical analysis." Sen (ibidem, p. 341) then continues: "But we also want an assumption structure that is not fundamentally at odds with the real world, nor one that makes simplicity take the form of naïvety." Most of us might react to that observation about as follows: We are well aware that the economic paradigm has some limitations, perhaps even some deficiencies or cracks. But it is still a powerful paradigm, and for the time being there does not seem to be a better substitute at the 
horizon. There have always been dissident views ${ }^{17}$, of course, but in recent years more economists began to think twice just how much at odds with the real world our assumption structure is and how close some of our simplifications come to naïveté.

To be more specific, consider our concepts of preferences, utility maximization and rational behavior. I do not only refer to the never-ceasing criticisms from psychologists and sociologists but also, and in particular, to the mounting empirical evidence mainly from experimental economics and game theory that people's behavior simply doesn't follow our concepts of utility maximization under constraints. Equilibrium strategies (Nash equilibria) which game theorists consider to constitute rational behavior in situations of strategic uncertainty about the other agents' actions systematically fail to be adopted by respondents in game experiments. Real-world agents' choices among lotteries, in particular when lotteries contain outcomes of low probability but high damage like environmental catastrophes, are at odds with von Neumann-Morgenstern expected utility theory which previously had been considered a firm basis for explaining decisions under uncertainty.

As a response to this evidence two polar reactions are conceivable. Either you reach the conclusion (for yourself) that some of our basic assumptions are fundamentally at odds with the real world. You give them up as a basis of descriptive, explicatory analysis thus restricting their use prescriptive, normative purposes (to show what rational decision makers should do). To fill the gap you replace 'maximizing' by concepts of bounded rationality, satisfying etc. In recent years this route is taken by quite a few economists, among them Nobel prize winner Reinhard Selten. ${ }^{18}$

The alternative reaction seems to be still more widespread: It reconciles empirical observations with the theory and thus avoids the conclusion that the assumptions are at odds with reality by taking advantage of the enormous flexibility of economic analysis and of the empirical voidness of the concept of preferences. A good example is the climate change issue and the somewhat intriguing observation that we could have a free lunch if consumers purchased all the energy-efficient utilities (e. g. energy saving light bulbs) which are already out there. The EEsts' (and economists') prototype reaction was, as aptly expressed by Shogren (1998, p. 565), that people "have or act as if they have a short time horizon" and: "Preferences are preferences - individual choices, however fuzzy, do match what society wants." We (and here I include myself) have become used to look at the real world in the light of our economic paradigm. ${ }^{19}$ But isn't it somewhat disturbing that we can explain just about everything? Doesn't that mean, empirical tests of theories are quite limited in their relevance and in their role as a judge to select "good" from "bad" theories. Haven't we a tendency to immunize our 'explanations' against empirical facts rather than - in a Popperian spirit - to accumulate empirically relevant new knowledge by making every effort to falsify our theories?

This is as far as I want to carry this argument. It is not my intention to initiate or contribute to a new methodological debates which, in my view, did not accomplish much more in the past than distracting researchers from constructive substantive work. I believe, however, that the

\footnotetext{
17 A recent sweeping attack on neoclassical (environmental) economics was launched by Sagoff (1994) who calls for abandoning the 'dogmas' of applied welfare economics.

${ }^{18}$ See Selten (1998) and Rubinstein (1998). It would be interesting to know how many (environmental) economists would agree to Selten's (1991; p. 19) position that it is better to use empirically tested ad-hoc assumptions than unrealistic principles of high generality and elegance.

19 Interestingly, Sterner and van den Bergh (1998, S. 254) react to Shogren's position by noting "that here are other views which suggest that people and firms are not striving for individual economic efficiency and optimality." Observe also that the debate on X-inefficiency proceeded along similar line some years ago.
} 
issue of preferences and rational behavior has the potential to significantly impact on the future of $\mathrm{EE}$ in case that more and more economists cross the line.

\section{The impact of environmental economics on shaping environmental policy}

Most EEsts who observed and/or participated in EP formation over the last decades would probably agree to characterize the development as follows: When environmental issues entered the agenda, pollution control was the domain of administrative law applying its traditional command and control approach. With their concepts of costs and benefits (non-market valuation) and market-based or incentive EP instruments EEsts were not able, for a long time, to effectively promote their ideas in intricate political decision-making processes. Some progress was made over time. But it can hardly be attributed to the EEsts' impatience alone that in politics far too little use was made of the substantial value added EE had to offer. This did not only cause frustration but also led some EEsts to search for the reasons 'why the patient did not follow the doctor's orders so well' (Hahn 1989) ${ }^{20}$. Among the well-known central arguments are:

(i) EEsts found it difficult to convey to the actors in the political arena the general rationale of their proposals. In the early days outright hostility towards EE was not uncommon. An important barrier to fruitful communication turned out to be that many of these actors lack basic knowledge of economics and of EE, in particular. With a background in other disciplines such as law, political science, sociology, ecology or engineering sciences decision makers, advisers and interest groups representatives compete for impacting on policy formation with an effort to shape the outcome according to their perceptions, interests and paradigms. After all, it was the economic activities that were the culprit for the environmental problems, and accepting advice based on economic concepts and methods would amount to hire the buck as a gardener (as a German proverb has it).

(ii) The advice EEsts offered was often based on abstract, conceptual analysis that didn't pay much attention to the complexities of the political decision making process, the importance of preexisting regulations and institutional arrangements (such as legal constraints, commands and controls) and to the costs of administration, monitoring and enforcement.

(iii) EEsts often consider their role as advocates for efficiency (Deacon et al. 1998, p. 384). However, in the political decision-making process many more criteria are taken into consideration, notably the distributional consequences of EP proposals (see above). Ignoring these criteria diminishes the prospects of political acceptability.

When these arguments are viewed against the discussion in the present paper it is quite obvious that reducing the major deficits identified in the sections 2 - 6 above will improve by and large the impact of EE on EP. To promote that objective in a more (pro)active way the EE research community may consider to develop a constructive research policy. Concerning the specific areas of activism and policy instruments I would suggest the following issues as particularly important and rewarding.

(a) Those who share the perception that too much research effort is allocated to theoretical and conceptual work 'in the ivory tower' and too little to 'down-to-earth' empirical and applied work (which Pezzey and Park (1998, p. 552) describe as "intellectually unglamorous but vital") might think about setting corrective incentives "to raise the place of rigorous applied research

\footnotetext{
${ }^{20}$ This question has been raised ever since the rise of EE. For an early contribution and an attempt to answer it see Haveman (1980).
} 
in the academic preference order " (Deacon et al. 1998, p. 395). Editors of journals, organizers of conferences and Ph.D. supervisors have considerable means and discretion in that respect.

(b) The observation that only few participants in policy debates "have a grasp of fundamental economic principles" (Schultze 1996) and hence analyze issues very differently from the economists' approach is vividly underlined by Shogren (1998) for EP in the U.S. We may hope that the number of students rises who earned a degree in EE or at least attended advanced courses in EE and who then will enter the political decision making process. But EEsts might perhaps want to adopt a more active strategy: Teaching programs and workshops for administrators, political decision-makers and future teachers - and thus pre-college students could be a promising way to improve upon the present unsatisfactory situation.

(c) But putting all the blame on the ignorance of others would be too simple. EEsts need to strive for a better understanding of the ways how non-economists and politicians analyze environmental issues and for more interdisciplinarity (see above). The latter is certainly desirable independent of policy implementation, but it also enhances acceptability. There are ways to redirect incentives for interdisciplinary work along the lines mentioned in point (a).

In an attempt to foster interdisciplinary research in Germany, the Deutsche Forschungsgemeinschaft (DFG) and the Volkswagenstiftung conditioned some research grants on proposals with substantial interdisciplinary aspects. As a result many pertaining proposals made strong commitments and 'promises' for genuinely interdisciplinary work, but the outcome did not always live up to these standards. Although some applicants' strategic behavior counteracts the DFG's good intentions, such research grants appear to be quite an effective catalytic devise to promote interdisciplinarity. (Money helps to overcome barriers).

(d) Point (iii) above indicates the need for a good understanding of the political decision making process as a precondition for the political acceptability of EP proposals. Therefore, greater attention on the positive theory of EP formation is desirable. Public Choice or the New Political Economy is by now a well-established field of study which aims at explaining the forces that drive the political process using economic methods. A clash is unavoidable if 'benevolent' EEsts 'in good faith' - or even naïve? - offer their EP advice without taking into account the pressures and constraints, self-interested political agents are exposed to when they are engaged in promoting their political career or their group's interests.

But what are the implications? Should we restrict our research to EP proposals we deem to be politically acceptable? While I agree that, we should pay more attention to the issue of political acceptability when offering EP advice, I have doubts whether our anticipation of acceptability or non-acceptability should be a primary criterion guiding our choice of research programs. For example, it is not clear to me that we should stop studying and suggesting revenue neutral ecological tax reforms, as recommended by Pezzey and Park (1998, p. 552). These authors argue that raising large emission tax revenues would face powerful resistance from interest groups, and therefore the future research should be directed towards zerorevenue market-based instruments whose acceptability is considered much greater.

The message of Public Choice analysis is, in my view, that EEsts interested in the implementation of research-based EP proposals should take into consideration that they become a part of the political decision-making process themselves, so-to-speak lobbyists for enhancing the rationality and efficiency of the process of EP formation. For lobbyists to be successful it is vital to know the rules of the game and to play the game according to those rules. The direct involvement of academic researchers in the policy implementation process is crucial, as Deacon et al. (1998, p. 394) point out correctly, since without such an involvement 
"... it seems unlikely, at least in the U.S., that state-of-the-art knowledge on benefits, costs and regulatory instruments will be reflected in actual policy choices."

The preceding considerations might help to improve the impact of EE on shaping EP in the future. But on the whole, there is no reason, in my view, to be pessimistic. In recent years the influence of EE on policy was already growing, slowly but steadily: We saw the advent of nonmarginal shifts toward ecological taxation in several European countries, the successful $\mathrm{SO}_{2}$ trading program in the U. S., the application of formal procedures of appraisal for EP regulation in the European Union (Pearce 1998), and a significant role of EEsts in the ongoing 'world-wide bargaining process' about how to cope with global climate change.

\section{Concluding remarks}

As mentioned in the introduction, the preceding discussion reflects many subjective appraisals and judgments which relate both to the current state of EE and to the topics of the future research agenda perceived as likely, necessary and/or desirable. While subjective components cannot be avoided in an enterprise like this, there is considerable scope for additional research, would be desirable to generate statistical or other hard evidence on the perceived strengths or deficits of EE. For example, how much empirically sound theoretical knowledge did we really accumulate and how does empirical research and hypothesis-testing compare with other economic areas, e. g. labor market economics? How much economy-environment interaction is accounted for in current EE research and what is the still unused potential to draw on other disciplines' ecology-related knowledge? By answering these types of questions on the basis of reliable facts and figures one could certainly promote successful corrective research policies.

Embarking on reflections about the future of EE entails the immediate risk to offer a large colorful bouquet of proposals for improvements. I am not sure whether I avoided the impression that, unless we adopt the ancient Olympic motto 'citius, altius, fortius' (faster, higher, stronger) there will no future for EE. During a relatively short period of time EE has been established as a thriving field of study attracting bright young (environmental) economists and impacting increasingly on practical EP. There is little reason to believe that this positive development will not continue. But if we direct additional efforts towards coping with the deficits identified in the discussion above we will certainly be able to do even better.

My reflections on the future of EE were based on the premise which I share with many EEsts that economic pressures will tend to put the ecological system under increasing stress (see section 6) and will thus geopardize the sustainable development of both the economic and the ecolocigal system, unless those with a similar perception, citizens, researchers and politicians alike, are successful in striving for effective remedy. There are different, much more optimistic assessments as expressed, e. g., in an article "Environmental scarces: Plenty of Gloom" in The Economist according to which "technology and economic freedom will make the world cleaner and will also take the pressure off endangered species". ${ }^{21}$ In this view future environmental problems, if there will be any, are going to be solved without particular effort and impact of EEsts who therefore are advised to close their files. I hope I made it clear that my perception of environmental issues, of the necessity of $\mathrm{EE}$ and of its future role is quite different. In that respect I join the contributors to the Policy Forum of Environmental and Development Economics (1998, Vol. 3, Part 4, 500-537) who responded to The Economist article.

\footnotetext{
21 The Economist, London, December 20, 1997; reprinted in Environmental and Development Economics, Vol.
} 3, Part 4, October 1998, p. 493 - 499; the quote is from page 499. 


\section{References}

Agee, M. D. and T. Crocker., 'Economies, human capital, and natural assets', in T. Sterner and J. C. M. van den Bergh (eds) (1998), 261 - 271

Arrow, K. J. et al. (1995), 'Economic growth, carrying capacity, and the environment', Science, 268, 520 - 521

Bingham, G. et al. (1995), 'Issues in ecosystem valuation: Improving information for decision making', Ecological Economic,s 14, 73 - 90

Blackorby, R. (1990), 'Economic policy in a second-best environment', Canadian Journal of Economics, 23, 748 - 771

Bockstael, N. E. (1996), 'Modeling economics and ecology: The importance of the spatial perspective', American Journal of Agricultural Economics, 78, 1168 - 1180

Bonus, H. (1986), 'Eine Lanze für den 'Wasserpfennig' - Wider die Vulgärform des Verursacherprinzips', Wirtschaftsdienst 66, 451 - 455

Bovenberg, A. L. and R. A. de Mooij (1994), 'Environmental levies and distortionary taxation', American Economic Review, 94, 1085 - 1089

Bromley, D. W. (ed.) (1995), Handbook of Environmental Economics. Oxford: Blackwell

Brunner, K. (1978), 'Reflections on the political economy of government. The persistent growth of government', Schweizerische Zeitschrift für Volkswirtschaft und Statistik, 114, $549-680$

Calthrop, E. and S. Proost (1998), 'Road transportation externalities', in T. Sterner and J. C. M. van den Bergh (eds) (1998), 335 - 348

Carraro, C. (1998), 'New economic theories', in T. Sterner and J. C. M. van den Bergh (eds) (1998), $365-381$

Carraro, C. and D. Siniscalco, eds. (1997), New Directions in the Economic Theory of the Environment. Cambridge: Cambridge University Press

Clark, C. W. (1990), Mathematical Bioeconomics, New York: Wiley

Coase, R. (1960), 'The problem of social cost', The Journal of Law and Economics, 3, 1 - 44

Constanza, R., C. Perrings and C. J. Cleveland (eds) (1997), The Development of Ecological Economics. Cheltenham, UK: Edward Elgar

Conrad, K. (1999), 'Computable general equilibrium models for environmental economics and policy analysis', in van den Bergh, J. C. M. (ed.), The Handbook of Environmental and Resource Economics, Cheltenham: Edward Elgar [forthcoming] 
Cropper, M. L. and W. E. Oates (1992), 'Environmental economics: A survey', Journal of Economic Literature, 30, 675 - 740

Daly, H. E. and K. N. Townsend, eds. (1993), Valuing the Earth: Economics, Ecology and Ethics, Boston: MIT Press

Deacon, R. T. et al. (1998), 'Research trends and opportunities in environmental and natural resource economics' in T. Sterner and J. C. M. van den Bergh (eds) (1998), 383 - 397

Debreu, G. (1959), Theory of Value: An Axiomatic Analysis of Economic Equilibrium, New York

Dixit, A. K. (1996), The Making of Economic Policy: A Transactions Cost Politics Perspective, Cambridge, MA: MIT Press

Eggert, H. (1998), 'Bioeconomics analysis and management', in T. Sterner and J. C. M. van den Bergh (eds) (1998), 399 - 411

Faber, M. and J. L. R. Proops (1990), Evolution, Time, Production and the Environment, Heidelberg: Springer-Verlag

Foster, B. A. (1972), 'A note on economic growth and environmental quality', Swedish Journal of Economics, 74, 281 - 286

Ginsburgh, V. and M. Keyzer (1997), The Structure of Applied General Equilibrium Models, Cambridge, MA, and London, England: MIT Press

Green, J. R., and J.-J. Laffont (1979), Incentives in Public Decision Making, North-Holland: Amsterdam, New York, Oxford

Hahn, R. (1989), 'Economic prescriptions for environmental problems: How the patient followed the doctor's orders', Journal of Economic Perspectives, 3, 94 - 114

Haveman, R. H. (1980), 'Public choice and public economics: The case of collective failure in U.S. water quality policy', in K. W. Roskamp (ed.), Public Choice and Public Finance, Paris: Editions Cujas, 137 - 154

Kneese, A. V. and J. L. Sweeney (eds) (1985/1993), Handbook of Natural Resource and Energy Economics, Vol. 1 - 3, Amsterdam: North-Holland

Levin, S. A. et al. (1998), 'Resilience in natural and socioeconomic systems', Environment and Development Economics, 3, 222 - 235

Lewis, T. (1996), 'Protecting the environment when costs and benefits are privately known', Rand Journal of Economics, 27, 819 - 847

Lipsey, R. G. and K. Lancaster (1956), 'The general theory of the second best', Review of Economic Studies, 24, 11 - 32 
Mäler, K.-G. (1974), Environmental Economics: A Theoretical Inquiry, Oxford: Blackwell

Markandya, A. (1998), 'Poverty, income distribution and policy making', in T. Sterner and J. C. M. van den Bergh (eds) (1998), 459 - 472

Markandya, A. and J. Richardson (eds) (1992), The Earthscan Reader in Environmental Economics, Earthscan

Meadows, D. H. et al. (1972), The Limits to Growth, New York

Norton, B., R. Constanza and R. C. Bishop (1998), 'The evolution of preferences - Why "sovereign" preferences may not lead to sustainable policies and what to do about it', Ecological Economics, 24, 191 - 212

Oates, W. E. (ed) (1992), The Economics of the Environment, Cheltenham: Edward Elgar

Pearce, D. W. (1998), 'Environmental appraisal and environmental policy in the European Union', in T. Sterner and J. C. M. van den Bergh (eds) (1998), 489 - 501

Perrings, C. (1998), 'Resilience in the dynamics of economy-environment systems', in T. Sterner and J. C. M. van den Bergh (eds) (1998), 503 - 520

Pezzey, J. C. V. and A. Park (1998), 'Reflections on the double dividend debate', in T. Sterner and J. C. M. van den Bergh (eds) (1998), 539 - 555

Rubinstein, A. (1998), Modeling Bounded Rationality, Cambridge, MA: MIT Press

Sagoff, M. (1994), 'Four dogmas of environmental economics', Environmental Values, 3, 285 310

Scitovsky, T. (1954), 'Two concepts of external economies', Journal of Political Economy, 62, $627-630$

Schultze, C. L. (1996), 'The CEA: An inside voice for mainstream economics', Journal of Economic Perspectives, 10, 23 - 39

Selten, R. (1998), 'Features of experimentally observed bounded rationality', European Economic Review, 42, 413 - 436

Selten, R. (1991), 'Evolution, learning and economic behavior', Games and Economic Behavior, 3, 3 - 24

Sen, A. K. (1985), 'Goals, commitment, and identity', Journal of Law, Economics and Organization, 1, 341 - 355

Shogren, J. F. (1998), 'A political economy in an ecological web', in T. Sterner and J. C. M. van den Bergh (eds) (1998), 557 - 570 
Siebert, H. (1985), 'Spatial aspects of environmental economics', in A. V. Kneese and J. L. Sweeney (eds), Handbook of Natural Resource and Environmental Economics, Amsterdam: North-Holland, 125 - 164

Siniscalco, D. (1998), 'Impacts of economic theories on environmental economics: Prospects', in J. C. M. van den Bergh (ed.), Handbook of Environmental and Resource Economics, Cheltenham, UK and Brookfield, US: Edward Elgar, [forthcoming]

Sterner, T. and J. C. M. van den Bergh (1998), 'Frontiers of Environmental and Resource Economics', in T. Sterner and J. C. M. van den Bergh (eds) (1998), 243 - 260

Sterner, T. and J. C. M. van den Bergh (eds) (1998), Frontiers of Environmental and Resource Economics: Testing the Theories; special issue of Environmental and Resource Economics, volume 11, Nos. 3 - 4

Stigler, G. J. and G. S. Becker (1977), 'De gustibus non est disputandum', American Economic Review, 67, 76 - 90

Tietenberg, H. and H. Folmer (eds) (1997, 1998), The International Yearbook of Environmental and Resource Economics 1997/1998 (1998/1999). Cheltenham, UK ans Brookfield, US: Edward Elgar

Tullock, G. (1967), 'Excess benefit', Water Resources Research, 3, 643 - 644

van den Bergh, J. C. M. (ed.) (1999), Handbook of Environmental and Resource Economics, Cheltenham, UK and Brookfield, US: Edward Elgar, [forthcoming]

van den Bergh, J. C. M. and P. Nijkamp (1991), 'Operationalizing sustainable development: Dynamic ecological economic models', Ecological Economics 4, 11 - 33

Wissenschaftsrat (1994), Stellungnahme zur Umweltforschung in Deutschland, Köln 